\title{
Legionella pneumophila-induced NF-кB- and MAPK-dependent cytokine release by lung epithelial cells
}

\author{
B. Schmeck*, P.D. N'Guessan*, M. Ollomang*, J. Lorenz*, J. Zahlten*,\#, B. Opitz*, \\ A. Flieger ${ }^{\star}$, N. Suttorp* and S. Hippenstiel*
}

ABSTRACT: Legionella pneumophila causes community-acquired pneumonia with high mortality, but little is known about its interaction with the alveolar epithelium. The aim of this study was to investigate whether $L$. pneumophila infection of lung epithelial cells (A549) resulted in proinflammatory activation.

L. pneumophila infection induced liberation of interleukin (IL)-2, -4, -6, -8 and -17, monocyte chemoattractant protein-1, tumour necrosis factor- $\alpha$, IL-1 $\beta$, interferon- $\gamma$ and granulocyte colonystimulating factor, but not of IL-5, $-7,-10,-12$ (p70) or -13 or granulocyte-macrophage colonystimulating factor. The present study focused on IL-8 and found induction by L. pneumophila strains 130b, Philadelphia 1, Corby and, to a lesser extent, JR32. Knockout of dotA, a central gene involved in type IVB secretion, did not alter IL-8 induction, whereas lack of flagellin significantly reduced IL-8 release by Legionella. Moreover, p38 mitogen-activated protein kinase (MAPK) was activated and kinase inhibition reduced secretion of induced cytokines, with the exception of IL-2 and granulocyte colony-stimulating factor. In contrast, inhibition of the MAPK kinase 1/ extracellular signal-regulated kinase pathway only reduced the expression of a few cytokines. L. pneumophila also induced binding of nuclear factor-кB subunit RelA/p65 and RNA polymerase II to the il8 promoter, and a specific inhibitor of the inhibitor of nuclear factor-кB complex dosedependently lowered IL-8 expression.

Taken together, Legionella pneumophila activated p38 mitogen-activated protein kinase- and nuclear factor-кB/RelA pathway-dependent expression of a complex pattern of cytokines by human alveolar epithelial cells, presumably contributing to the immune response in legionellosis.

KEYWORDS: Alveolar epithelium, bacteria, cytokines, signal transduction pathways

A $\mathrm{n}$ important causative agent of severe community-acquired pneumonia, Legionella pneumophila is the second most commonly detected pathogen in cases of pneumonia admitted to intensive care units in industrialised countries [1]. Approximately 15\% of legionellosis appears in community outbreaks. Although $>40$ Legionella species are known, the majority of human infections are caused by $L$. pneumophila serogroup 1 [2]. L. pneumophila is a Gram-negative facultative intracellular pathogen of amoeba in natural and man-made aquatic environments. Infection of humans occurs after inhalation of contaminated water aerosol droplets. L. pneumophila-containing phagosomes initially do not fuse with lysosomes and the bacteria induce remodelling of their membranebound compartment into an endoplasmic reticulum-like organelle [3]. This remodelling depends on the defect in organelle trafficking
(Dot)/intracellular multiplication (Icm) type IVB secretion apparatus of L. pneumophila [4]. Besides delivery of proteins by the type IVB secretion system, L. pneumophila contains a battery of additional virulence factors, including a type II secretion apparatus [3]. Sequencing of L. pneumophila serogroup 1 genomes revealed $\sim 3,000$ genes, among which are many genes with possible function in manipulation of host cell signalling [5].

According to the Legionella-host interaction, recent studies demonstrated that L. pneumophila lipopolysaccharide was recognised by Toll-like receptor (TLR) 2 and flagellin by TLR5 [6, 7]. A stop codon in the human TLR5 gene leads to increased susceptibility to legionellosis [7]. Interestingly, although some studies have suggested a minor role of TLR4 in legionellosis [6], HAwn et al. [8] recently showed that TLR4

\section{AFFILIATIONS}

${ }^{*}$ Dept of Internal Medicine/Infectious Diseases and Respiratory Medicine and

\# Institute for Periodontology and Synoptic Dentistry, Charité Universitätsmedizin Berlin, and 'Nachwuchsgruppe 5 Pathogenesis of Legionella Infection, Robert Koch Institute, Berlin, Germany.

\section{CORRESPONDENCE}

S. Hippenstiel

Dept of Internal Medicine/Infectious

Diseases and Respiratory Medicine Charité - Universitätsmedizin Berlin Augustenburger Platz 1

13353 Berlin

Germany

Fax: 4930450553906

E-mail: stefan.hippenstiel@

charite.de

Received:

November 302005

Accepted after revision:

August 072006

SUPPORT STATEMENT

This study was supported, in part, by the Federal Ministry of Education and Research (BMBF; Berlin, Germany): B. Schmeck, BMBF-competence network community-acquired pneumonia (CAPNETZ) C15; S. Hippenstiel, BMBF-CAPNETZ C15 and N. Suttorp and S. Rosseau, BMBF-CAPNETZ C4. The German Society for Pneumology (Werne Germany) also provided support for this study: S. Hippenstiel and J. Zahlten. 
polymorphisms are associated with resistance to Legionnaires' disease.

Essential results according L. pneumophila pathogenesis were obtained by analysing infection of protozoans or immune cells such as macrophages. However, lung epithelial cells constitute a first mechanical and immunological barrier against airborne pathogens and are important sources of cytokines in the lung $[9,10]$. Activation of pro-inflammatory signalling pathways in lung epithelial cells, including p38 mitogen-activated protein kinase (MAPK)- and nuclear factor- $\kappa \mathrm{B}$ (NF- $\mathrm{KB}$ )-dependent gene transcription, by bacterial infection, contribute significantly to cytokine release [10, 11]. Although Legionella efficiently infects and stimulates lung epithelial cells [7, 12], mechanisms of L. pneumophila-induced activation of and cytokine release in lung epithelial cells are widely unknown. Therefore, the pro-inflammatory activation of lung epithelial cells by Legionella infection was analysed in detail.

In the present study, it was shown that L. pneumophila induced the release of several important cytokines in human alveolar epithelial A549 cells, e.g. interleukin (IL)-2, -4, -6, -8 and -17, monocyte chemoattractant protein (MCP)-1, tumour necrosis factor (TNF)- $\alpha$, IL-1 $\beta$, interferon (IFN)- $\gamma$ and granulocyte colony-stimulating factor (G-CSF), as well as activating the p38 MAPK, extracellular signal-regulated kinase (ERK) and NF- $\kappa$ B pathways. Blocking p38 MAPK reduced secretion of all cytokines in Legionella-infected cells, with the exception of IL2 and G-CSF, whereas blocking the ERK pathway diminished only release of IFN- $\gamma$, IL-1 $\beta$, IL- 6 and TNF- $\alpha$. By addressing expression of IL-8 as a model cytokine in more detail, the important role of p38 MAPK- and NF- $\mathrm{kB} /$ RelA-dependent gene transcription in the activation of L. pneumophila-infected epithelial cells was verified. Moreover, activation of IL-8 expression was reduced by a flagellin deletion mutant, implying a role for TLR5 or possible intracellular receptors in Legionella sensing by A549 cells. However, IL-8 expression in A549 cells was not affected by a $\operatorname{dot} A$-knockout mutant, suggesting that the type IVB Dot/Icm secretion system and intracellular replication are not needed for IL-8 expression in A549 cells.

\section{MATERIALS AND METHODS \\ Cell lines}

Alveolar epithelial cell line A549 was purchased from the American Type Culture Collection (ATCC; Rockville, MD, USA) and cultured in Ham's F-12 medium with L-glutamine and $10 \%$ foetal calf serum (Life Technologies, Karlsruhe, Germany) without antibiotics. The NF-кB-dependent reporter cell line, A549 6Btkluc, was a kind gift of R. Newton (Dept of Biological Sciences, University of Warwick, Coventry, UK). These cells contain a stably integrated plasmid with three tandem repeats of the sequence $5^{\prime}$-AGCTTACAAGGGACTTTCCGCTGGGGACTTTCCAGGGA-3', which contains two copies of the decameric NF- $\kappa$ B binding site upstream of a minimal thymidine kinase promoter (-105-51) driving a luciferase gene.

\section{Infection with bacterial strains and isogenic mutants}

L. pneumophila sg1 strains 130b (ATCC BAA-74, kindly provided by N.P. Cianciotto, Northwestern University Medical School, Chicago, IL, USA [13]), Philadelphia 1
(ATCC 33152, kindly provided by B. Neumeister, Tübingen University, Tübingen, Germany [14]), JR32 wildtype [15] and JR32 $\operatorname{dot} A$ mutant (LELA 3118, both kindly provided by $\mathrm{H}$. Shuman, Columbia University, New York, NY, USA [16]), and Corby wildtype and a Corby fla $A$, defective in flagellin, mutant (both kindly provided by K. Heuner, Würzburg University, Würzburg, Germany) were routinely grown on buffered charcoal-yeast extract (BCYE) agar for $2-3$ days at $37^{\circ} \mathrm{C}$ [17] and subsequently inoculated into plain RPMI medium at an optical density at $660 \mathrm{~nm}$ of $0.2-0.4$. A549 cells $\left(1 \times 10^{5}\right.$ cells $\left.\cdot \mathrm{mL}^{-1}\right)$ were infected with $1 \times 10^{5}-1 \times 10^{8}$ colonyforming units $(\mathrm{cfu}) \cdot \mathrm{mL}^{-1}$ L. pneumophila, i.e. at a multiplicity of infection of 1:1-1:1,000, in $1 \mathrm{~mL}$ epithelial cell growth medium for the indicated times. Extracellular bacteria were not routinely killed with antibiotics. L. pneumophila strains did not grow significantly in epithelial cell growth medium, as controlled by serial dilutions plated on BCYE agar.

In order to verify intracellular infection, A549 cells were incubated with the added bacteria for $2 \mathrm{~h}$ with or without kinase inhibitors, gentamicin $\left(100 \mu \mathrm{g} \cdot \mathrm{mL}^{-1}\right)$ was added for a further $2 \mathrm{~h}$ and then the cells were washed three times with plain medium, to remove unbound bacteria, and treated with $10 \%$ (weight/volume) saponin (Sigma Chemical Company, Munich, Germany) to lyse the host cells. Serial dilutions were plated on BCYE agar.

\section{Interleukin-8 ELISA}

Confluent A549 cells were infected as indicated in a humidified atmosphere for $15 \mathrm{~h}$. After incubation, supernatants were collected and processed for IL-8-quantification by sandwich ELISA, as described previously [11, 18]. In some experiments, medium was changed after certain time periods (1, 2 or $4 \mathrm{~h}$ ) with or without gentamicin $\left(100 \mu \mathrm{g} \cdot \mathrm{mL}^{-1}\right)$ and then the cells were incubated for the remaining time in the same medium before IL-8 was analysed in the supernatant.

\section{Bioplex protein array system}

Confluent A549 cells were infected as indicated in a humidified atmosphere for $15 \mathrm{~h}$. After incubation, supernatants were collected and cytokine release was analysed using the Bioplex Protein Array system (BioRad, Hercules, CA, USA) and beads specific for IL-2, $-4,-5,-6,-7,-8,-10,-12$ (p70), -13 and -17 , MCP-1, TNF- $\alpha$, IL- $1 \beta$, IFN- $\gamma$, granulocyte-macrophage colonystimulating factor (GM-CSF) and G-CSF, according to the manufacturer's instructions [19, 20].

\section{Western blotting}

For determination of p38 MAPK and ERK phosphorylation, A549 cells were infected as indicated, washed twice and harvested. Cells were lysed in buffer containing Triton X-100 (Sigma Chemical Company), subjected to sodium dodecylsulphate-polyacrylamide gel electrophoresis and blotted on to Hybond ECL membrane (Amersham Biosciences, Freiburg, Germany). Immunodetection of phosphorylated MAPK was carried out using phospho-specific p38 MAPK or ERK antibodies (Cell Signaling, Frankfurt, Germany) [11]. Degradation of inhibitor of NF- $\kappa \mathrm{B}(\mathrm{I} \kappa \mathrm{B} \alpha)$ was analysed using a rabbit polyclonal antibody (Santa Cruz Biotechnologies, Santa Cruz, CA, USA) as described previously [11]. In all experiments, unphosphorylated ERK2 and p38 

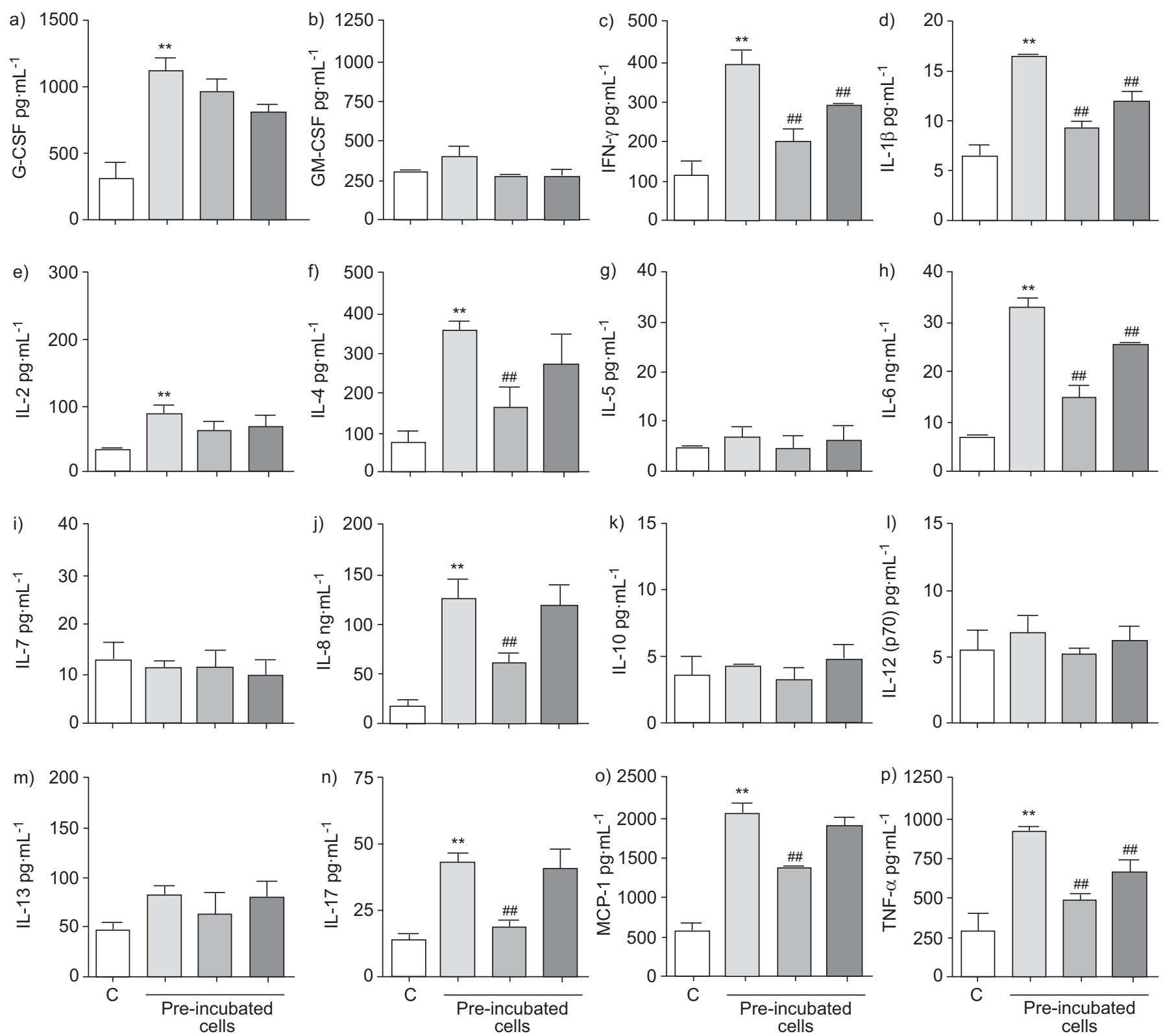

FIGURE 1. Legionella pneumophila-induced release of a cytokine pattern mainly dependent on p38 mitogen-activated protein kinase (MAPK) activity: a) granulocyte colony-stimulating factor (G-CSF); b) granulocyte-macrophage colony-stimulating factor (GM-CSF); c) interferon (IFN)- $\gamma$; d) interleukin (IL)-1 13 ; e) IL-2; f) IL-4; g) IL-5; h) IL-6; i) IL-7; j) IL-8; k) IL-10; I) IL-12 (p70); m) IL-13; n) IL-17; o) monocyte chemoattractant protein (MCP)-1; and p) tumour necrosis factor (TNF)- $\alpha$. A549 cells ( $1 \times 10^{5}$ cells-mL ${ }^{-1}$ ) were pre-incubated (30 min) with medium alone ( $\square$ ) 5 5 M SB202190 (p38 MAPK inhibitor; $\square$ ) or U0126 (MAPK kinase 1 inhibitor; $\square$ ) and infected with L. pneumophila 130b $\left(1 \times 10^{7}\right.$ colony-forming units $\cdot \mathrm{mL}^{-1}$; uninfected control $\left.(\mathrm{C} ; \square)\right)$. Cytokine release in the supernatant was measured by Bioplex assay. Data are presented as mean \pm SEM. ${ }^{* *}$. $p<0.01$ versus $C$; $\#$ :\# $p<0.01$ versus infected cells without pre-incubation with inhibitors (in at least three independent experiments).

MAPK (Santa Cruz Biotechnologies) were detected simultaneously in order to confirm equal protein load. Proteins were visualised by incubation with secondary IRDye 800- or Cy5.5labelled antibodies, respectively (Odyssey infrared imaging system; LI-COR Inc., Bad Homburg, Germany) [11, 21]. All primary antibodies were used at a dilution of 1:200 and all secondary antibodies at a dilution of 1:2,000.

\section{$R T-P C R$}

For analysis of IL-8 and reduced glyceraldehye-3-phosphate dehydrogenase (GAPDH) gene expression in A549 cells, total
RNA was isolated by means of the RNEasy Mini kit (Qiagen, Hilden, Germany) and reverse transcribed using avian myeloblastosis virus reverse transcriptase (Promega, Heidelberg, Germany). The complementary DNA generated was amplified by PCR using specific intron-spanning IL-8 and GAPDH primers [11]. All primers were purchased from TIB MOLBIOL (Berlin, Germany). After 35 amplification cycles, PCR products were analysed on $1.5 \%$ agarose gels, stained with ethidium bromide and subsequently visualised. In order to confirm use of equal amounts of RNA in each experiment, all samples were checked for GAPDH mRNA expression. 


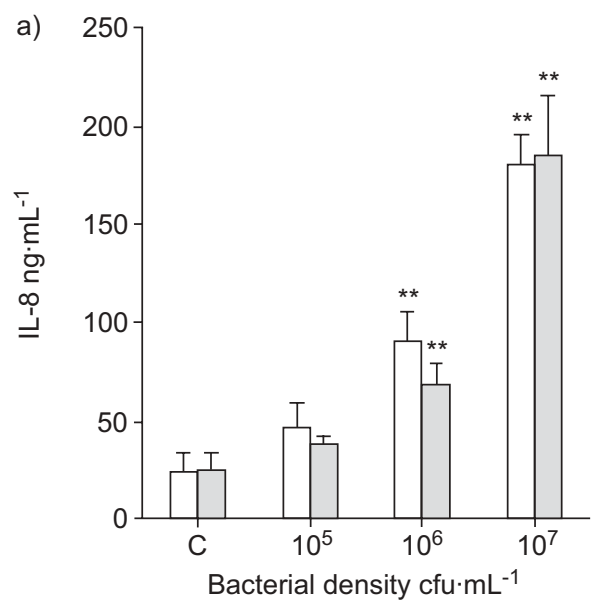

b)

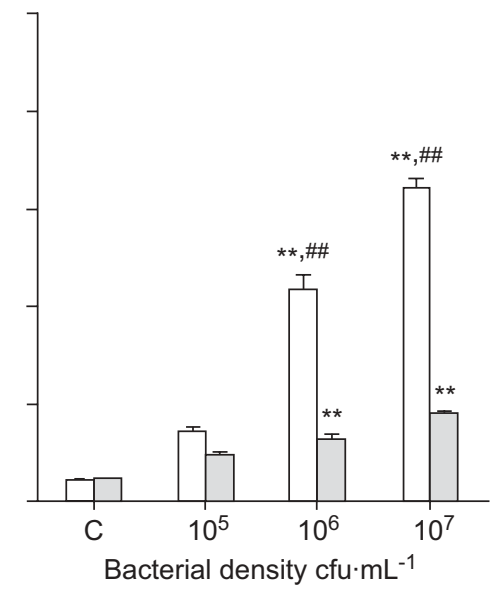

e)

d)

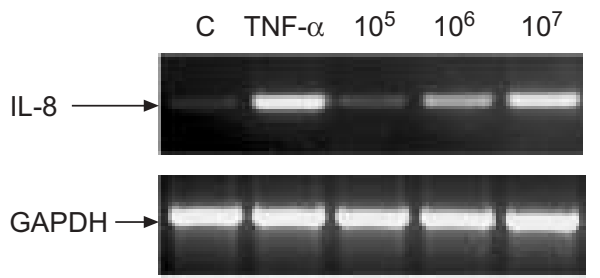

Bacterial density cfu $\cdot \mathrm{mL}^{-1}$

(1)

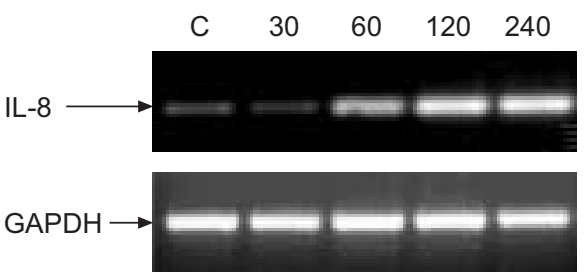

c)

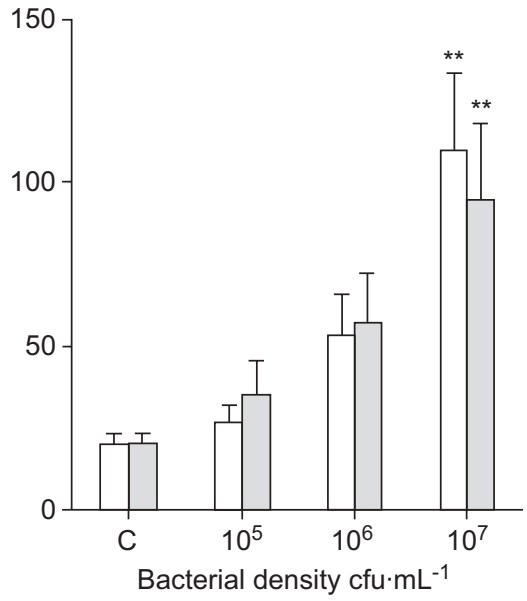

FIGURE 2. Induction of flagellin-dependent dotA-independent interleukin (IL)-8 expression in alveolar epithelial cells by various Legionella pneumophila strains. A549 cells $\left(1 \times 10^{5}\right.$ cells $\left.\cdot \mathrm{mL}^{-1}\right)$ were infected with L. pneumophila: a) $130 \mathrm{~b}(\square)$ and Philadelphia 1 ( $\square$ ); b) Corby wildtype $(\square)$ and $\Delta$ flaA knockout mutant ( $\square$ ); c) JR32 wildtype $(\square)$ and $\Delta$ dotA knockout mutant $(\square)$; d, e) 130b; and f) JR32 wildtype and $\Delta$ dotA knockout mutant. a-c) IL-8 release into the supernatant following treatment at the indicated bacterial densities was measured by ELISA after $15 \mathrm{~h}$. Data are presented as mean \pm SEM. $\mathrm{d}-\mathrm{f}$ ) IL-8 and reduced glyceraldehye-3-phosphate dehydrogenase (GAPDH) mRNA expression were determined by RT-PCR: d) $4 \mathrm{~h}$ after infection with the indicated concentrations of $L$. pneumophila or after incubation for $4 \mathrm{~h}$ with $100 \mathrm{ng} \cdot \mathrm{mL}^{-1}$ tumour necrosis factor- $\alpha$ (TNF- $\alpha$ ); and e, f) at the indicated time points after infection with $1 \times 10^{7}$ colony-forming units (cfu) $\cdot \mathrm{mL}^{-1} \mathrm{~L}$. pneumophila (representative gels of three are shown). ${ }^{*}$ : $\mathrm{p}<0.01$ versus uninfected control (C); ${ }^{\# \#: ~} \mathrm{p}<0.01$ versus Philadelphia 1 or mutant.

\section{Reporter gene assay}

A549 cells stably transfected with a NF-кB-dependent luciferase reporter plasmid [22] were cultured in 12-well plates in Dulbecco's modified Eagle medium (Life Technologies). Cells were incubated with Legionella for $15 \mathrm{~h}$ and lysed, and then luciferase activity was measured using a luciferase reporter gene assay (Promega, Mannheim, Germany).

\section{Chromatin immunoprecipitation}

A549 cells in $75-\mathrm{cm}^{2}$ culture flasks were infected with $L$. pneumophila $130 \mathrm{~b}$ as indicated and then subjected to a chromatin immunoprecipitation assay, as previously described, using anti-p65 or anti-RNA polymerase II antibodies (both Santa Cruz Biotechnologies) [11, 20]. The il8 promoter was amplified by PCR using HotstarTaq polymerase (Qiagen) and specific primers as follows: 5'AAGAAAACTTTCGTCATACTCCG-3' (sense); and 5'TGGCTTTTTATATCATCACCCTAC-3' (antisense). PCR amplification of the total input DNA in each sample was performed as a control [18, 19].

\section{Statistical methods}

Data are presented as mean \pm SEM of at least three independent experiments. One-way ANOVA was used for numerical data shown in the figures. Main effects were then compared using
Newman-Keuls post-test. A p-value of $<0.01$ was considered significant.

\section{RESULTS \\ Cytokine release}

In order to characterise inflammatory activation of human alveolar epithelial cells by L. pneumophila, $1 \times 10^{5}$ A549 cells were infected with L. pneumophila strain $130 \mathrm{~b}$ at an infection dose of $1 \times 10^{7} \mathrm{cfu} \cdot \mathrm{mL}^{-1}$, i.e. a multiplicity of infection of 1:100. Cytokine release was analysed using a Bioplex assay. After incubation for $15 \mathrm{~h}$, significant induction of IL-2, -4, -6, -8 and -17 , MCP-1, TNF- $\alpha$, IL-1 $\beta$, IFN- $\gamma$ and G-CSF, but not of IL-5, -7 , $-10,-12$ (p70) or -13 or GM-CSF was observed (fig. 1). Pre-incubation of A549 cells with the specific p38 MAPK inhibitor SB202190 (Calbiochem-Merck, Darmstadt, Germany) reduced levels of IL-4, $-6,-8$ and -17 , MCP-1, TNF- $\alpha$, IL-1 $\beta$ and IFN- $\gamma$, but not of IL-2 or G-CSF (TNF- $\alpha$ was obtained from R\&D Systems, Wiesbaden, Germany). Inhibition of MAPK kinase 1 (MEK1) by U0126 reduced release of only IFN- $\gamma$, IL$1 \beta$, IL- 6 and TNF- $\alpha$ (fig. 1). Incubation with inhibitors alone showed no cytotoxicity and did not alter cytokine expression or infection of epithelial cells (data not shown).

Flagellin- and dotA-dependency of interleukin-8 expression Alveolar epithelial cell activation was analysed in more detail by addressing the expression of the important chemotactic 

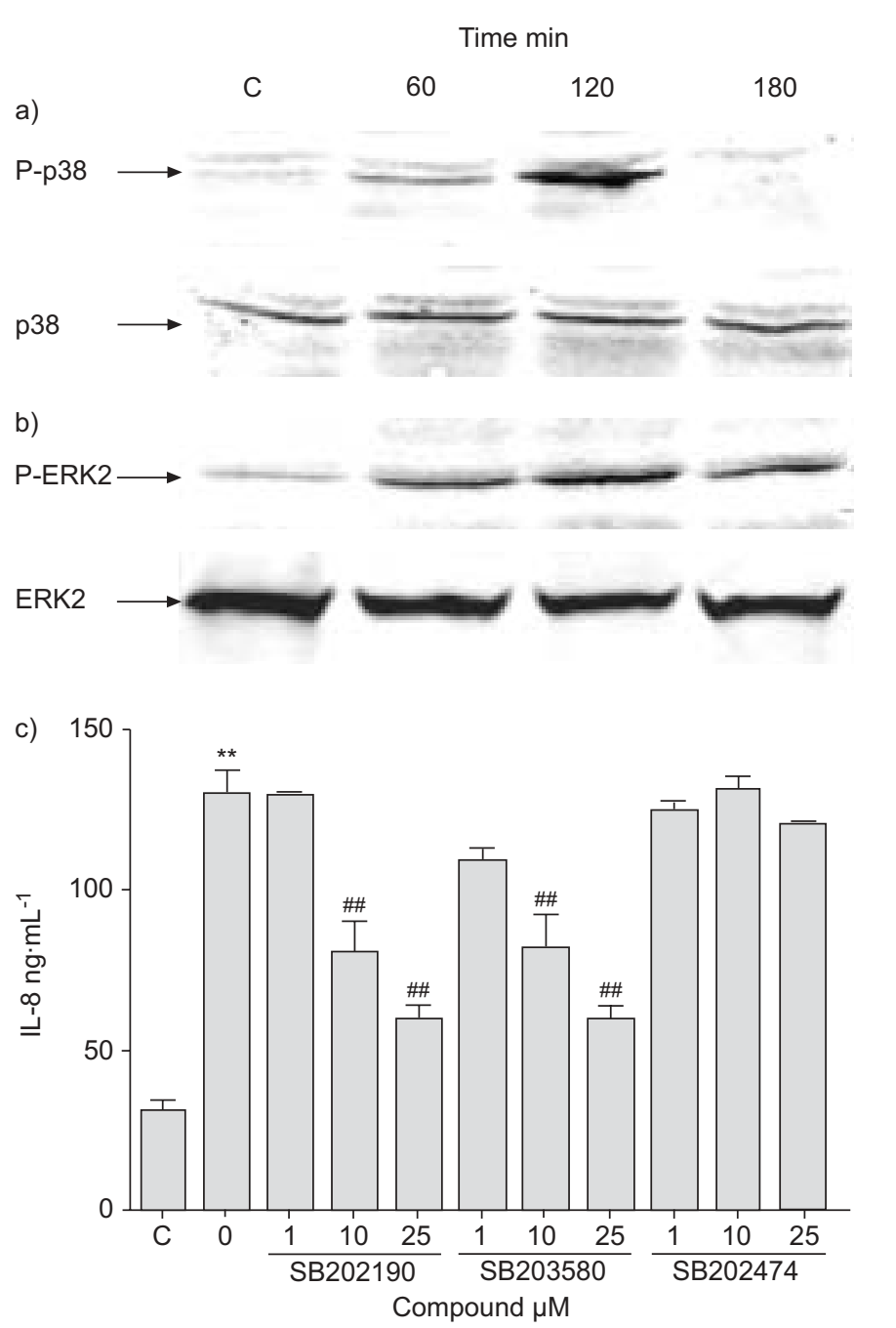

d)
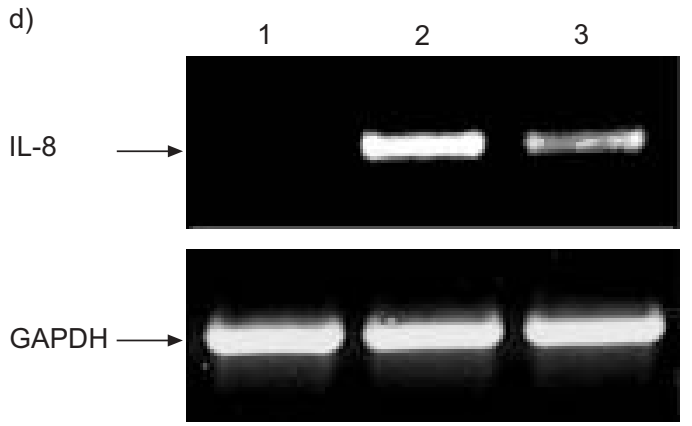

FIGURE 3. Legionella pneumophila-induced interleukin (IL)-8 release dependency on p38 mitogen-activated protein kinase (MAPK) activation in alveolar epithelial cells. A549 cells $\left(1 \times 10^{5}\right.$ cells $\left.\cdot \mathrm{mL}^{-1}\right)$ were infected with $L$. pneumophila $130 \mathrm{~b}\left(1 \times 10^{7}\right.$ colony-forming unit $\left.\cdot \mathrm{mL}^{-1}\right)$. Phosphorylation (P) of a) p38 MAPK and b) extracellular signal-regulated kinase (ERK)2 were determined at the indicated time points by Western blot analysis (representative blots of three are shown). c, d) A549 cells were pre-incubated ( $30 \mathrm{~min}$ ) with $10 \mu \mathrm{M} \mathrm{SB202190} \mathrm{(c} \mathrm{and} \mathrm{d),} \mathrm{SB203580}$ (c) and SB202474 (c) and infected with L. pneumophila 130b. c) IL-8 release in the supernatant was measured by ELISA after $15 \mathrm{~h}$. Data are presented as mean \pm SEM d) IL-8 mRNA was detected by RT-PCR after $4 \mathrm{~h}$ (lane 1: uninfected control (C); lane 2: cells pre-incubated with medium alone; lane 3: pre-incubated cells). GAPDH: reduced glyceraldehye-3-phosphate dehydrogenase. ${ }^{*}: p<0.01$ versus $C$; ${ }^{\# \#}$ $p<0.01$ versus infected cells not pre-incubated with inhibitors (in at least three independent experiments). cytokine IL-8. A549 cells were infected with various concentrations of L. pneumophila strains 130b, Philadelphia 1, JR32 and Corby for $15 \mathrm{~h}$ (fig. 2). L. pneumophila 130b, Philadelphia 1 and Corby similarly induced dose-dependent IL-8 release (fig. 2a and b), whereas JR32-provoked cytokine secretion was lower (fig. 2c). L. pneumophila 130b also induced dose- (fig. 2d) and time-dependent (fig. 2e) expression of IL-8 mRNA. Gene expression started as early as $60 \mathrm{~min}$ after infection. A fla $\mathrm{A}$ knockout mutant, defective in flagellin production, resulted in strongly reduced IL-8 release by L. pneumophila Corby-infected A549 cells over $15 \mathrm{~h}$ (fig. $2 \mathrm{~b}$ ). In contrast, a $\operatorname{dot} A$ knockout mutant, defective in a gene essential for the establishment of a functional L. pneumophila type IVB secretion apparatus [3], did not alter IL-8 release by L. pneumophila JR32-infected A549 cells over $15 \mathrm{~h}$ (fig. 2c) or the time course of IL-8 mRNA induction up to $4 \mathrm{~h}$ (fig. $2 \mathrm{f}$ ).

\section{Interleukin-8 release dependency on p38 mitogen-activated protein kinase activation}

Next, L. pneumophila-induced activation of mitogen-activated kinase pathways was analysed. A549 cells were infected with L. pneumophila 130b, and phosphorylation of p38 MAPK (fig. 3a) and ERK2 (fig. 3b) was assessed by Western blot analysis. L. pneumophila infection induced phosphorylation of both kinases within 60-120 min. Blocking p38 MAPK with SB202190 reduced IL-8 mRNA accumulation (fig. 3d). Moreover, p38 MAPK inhibitors SB202190 and SB203580 (Calbiochem-Merck) dose-dependently reduced L. pneumophilainduced IL-8 release (fig. 3c). Control compound SB202474 (Calbiochem-Merck) had no effect on cytokine release (fig. 3c). Neither inhibitors nor control compound reduced cell number or induced morphological signs of cytotoxicity.

\section{Interleukin-8 release dependency on nuclear factor- $\kappa B$ activation}

Activation of the IL- 8 promoter is considered to require

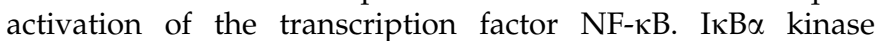
complex was blocked using the specific peptide inhibitor, IкB kinase NF- $\kappa B$ essential modulator-binding domain (IKK-NBD; Biomol, Plymouth Meeting, PA, USA), and a dose-dependent reduction in IL-8 secretion by $L$. pneumophila $130 \mathrm{~b}$-infected A549 cells observed (fig. 4a). In A549 cells, transfected with a NF- $\kappa \mathrm{B}-$ dependent reporter gene construct, dose-dependent induction of reporter gene expression was found (fig. 4b). IKK-NBD displayed no cytotoxicity and did not alter infection of A549 by Legionella strain 130b or basal cytokine expression (data not shown). Western Blot analysis revealed degradation of cytosolic NF- $\kappa \mathrm{B}$ inhibitor I $\mathrm{KB} \alpha$ starting $60 \mathrm{~min}$ after stimulation of A549 cells with L. pneumophila 130b (fig. 4c), and chromatin immunoprecipitation showed recruitment of NF$\mathrm{\kappa B} / \mathrm{p} 65$ and RNA polymerase II to the il8 promoter (fig $4 \mathrm{~d}$ ). IKKNBD did not reduce cell number or induce morphological signs of cytotoxicity. These data indicate that L. pneumophila induces IL-8 expression by activation of the canonical NF- $\mathrm{BB}$ pathway.

\section{Effect of gentamicin on interleukin-8 release}

In order to address the importance to cellular activation of $L$. pneumophila remaining extracellular, the medium was changed after infection periods of 1,2 and $4 \mathrm{~h}$ in the presence and absence of gentamicin and IL-8 release analysed after a total infection time of $15 \mathrm{~h}$ (fig. 5). Removal of extracellular bacteria 


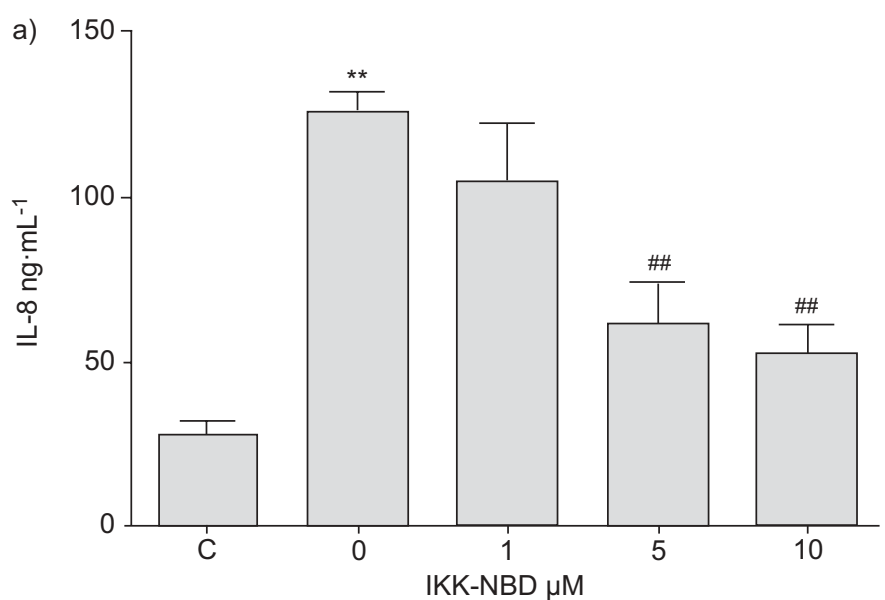

c)

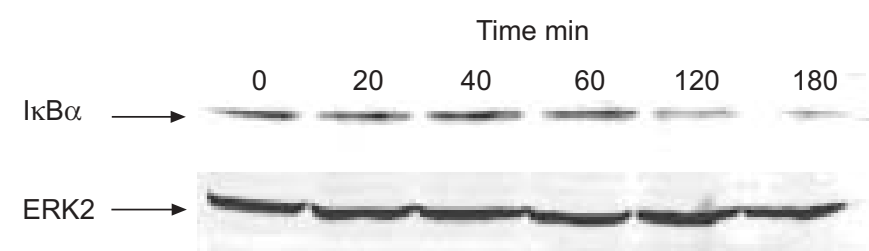

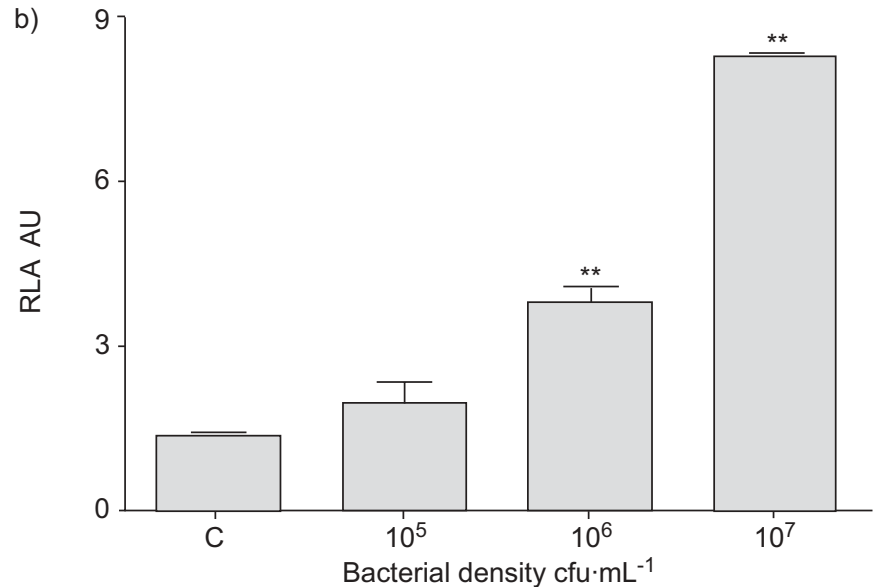

d)

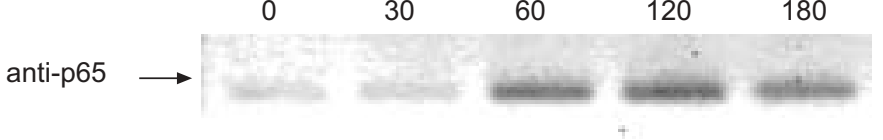

anti-Pol II $\longrightarrow$

Lysate

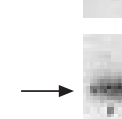

FIGURE 4. Legionella pneumophila-induced interleukin (IL)-8 release dependency on nuclear factor- $\mathrm{KB}$ (NF-kB) activation in alveolar epithelial cells. a) A549 cells $\left(1 \times 10^{5}\right.$ cells $\left.\cdot \mathrm{mL}^{-1}\right)$ were pre-incubated with the indicated concentrations of inhibitor of NF- $\mathrm{KB}(\mathrm{k} \mathrm{K})$ kinase NF- $\mathrm{kB}$ essential modulator-binding domain and infected with $\mathrm{L}$. pneumophila 130b $\left(1 \times 10^{7}\right.$ colony-forming units $\left.(\mathrm{cfu}) \cdot \mathrm{mL}^{-1}\right)$. IL-8 release in the supernatant was measured by ELISA. b) Relative luciferase activity (RLA) was determined in A549 cells stably transfected with a NF-KB-dependent reporter gene construct $6 \mathrm{~h}$ after infection with L. pneumophila 130b. Data are presented as mean \pm SEM. C) Degradation of $\mathrm{I} \mathrm{KB} \alpha$ was determined at the indicated time points after infection with $1 \times 10^{7} \mathrm{cfu} \cdot \mathrm{mL}^{-1} \mathrm{~L}$. pneumophila $130 \mathrm{~b}$ by Western blot analysis (representative blots of three are shown). d) Recruitment of NF-kB/p65 and RNA polymerase II (Pol II) to the il/ promoter was determined at the indicated time points after infection with $1 \times 10^{7} \mathrm{cfu} \cdot \mathrm{mL}^{-1} \mathrm{~L}$. pneumophila 130b by chromatin immunoprecipitation (precipitating antibodies are as indicated; the initial cell lysate without immunoprecipitation is also shown for comparison; representative blots/gels of three are shown). AU: arbitrary unit; ERK: extracellular signal-regulated kinase. ${ }^{* *}: p<0.01$ versus uninfected control (C); ${ }^{\# \# *}: p<0.01$ versus infected cells without pre-incubation with inhibitors (in at least three independent experiments).

early in infection resulted in significantly reduced IL-8 release in comparison with late removal after $4 \mathrm{~h}$ of infection. Moreover, killing of extracellular bacteria with gentamicin further reduced IL-8 release.

\section{DISCUSSION}

In the present study, it was found that L. pneumophila $130 \mathrm{~b}$ induced release of a complex cytokine pattern by human alveolar epithelial cell line A549. Detailed analysis of IL-8 release showed similar IL-8 expression in cells infected with L. pneumophila strains 130b, Philadelphia 1 and Corby. IL-8 secretion depended on activation of the p38 MAPK and canonical NF- $\kappa \mathrm{B} /$ RelA-pathway, and, to a lesser extent, the MEK1-ERK1/2 pathway (fig. 6).

Lung epithelial cells have important functions in innate immunity, e.g. they recognise pathogens, including bacteria, via TLRs and release antibacterial peptides, as well as chemotactic and pro-inflammatory cytokines $[9,10]$. Although alveolar epithelial cells were infected efficiently by Legionella in vitro [12, 23], and in vivo in guinea pigs [12], knowledge about host immunoreaction against L. pneumophila mainly arises from studies with human monocytes/macrophages and animal studies in the Legionella-permissive naip5 locus-defect A/J mouse strain [24].

Since chemokine synthesis is important for orchestration of the innate and adaptive immune response, the chemokine pattern released by L. pneumophila-infected alveolar epithelial cells was analysed first. For this purpose, the well-established human alveolar epithelial cell line A549, which Legionella infects efficiently, as shown in several studies $[12,23]$, was used.

L. pneumophila-infected A549 cells released the chemoattractants IL-8 (for polymorphonuclear neutrophils (PMNs)) and MCP-1 (for monocytes), the T-helper cell (Th) type 1 cytokines IL-2, TNF- $\alpha$ and IFN- $\gamma$, and the Th2 cytokines IL- 4 and IL-6 within $15 \mathrm{~h}$. In addition, the pro-inflammatory cytokines IL-1 $\beta$ and IL-17 and the myeloid growth factor G-CSF were secreted (fig. 6). In accordance with the present findings, CHANG et al. [23] described IL-6 and IL-8, as well as TNF- $\alpha$, expression in Legionella-infected A549 cells. 


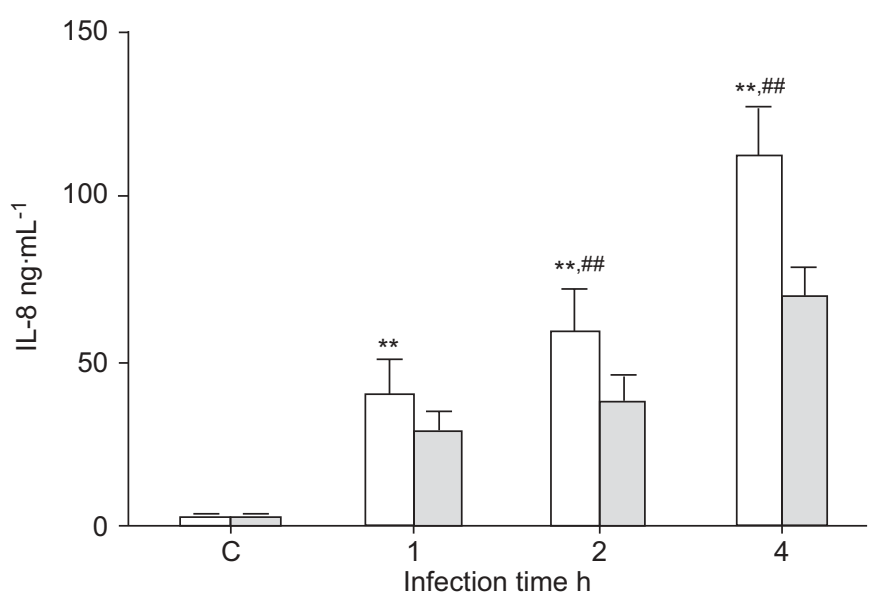

FIGURE 5. Legionella pneumophila-induced interleukin (IL)-8 release was reduced by gentamicin. A549 cells $\left(1 \times 10^{5}\right.$ cells $\left.\cdot \mathrm{mL}^{-1}\right)$ were infected with $L$. pneumophila $130 \mathrm{~b}\left(1 \times 10^{7}\right.$ colony-forming units $\left.\cdot \mathrm{mL}^{-1}\right)$. The medium was changed after the indicated time period, with $(\square)$ or without $(\square)$ addition of gentamicin. IL-8 release in the supernatant was measured by ELISA after a total incubation time of 15 h. ${ }^{* *}: p<0.01$ versus uninfected control $(C) ;{ }^{\# \#: ~} p<0.01$ versus infected cells with addition of gentamicin (in at least three independent experiments).

In humans, Legionella infection increases serum levels of, for example, IFN- $\gamma$ and IL-6, -12 and $-10[25,26]$. In experimental studies using murine models or isolated macrophages, mainly cytokines attracting and activating PMNs and moncytes/ macrophages have been analysed. In experimental Legionella pneumonia in A/J mice, TATEDA et al. [27] found induction of the chemotactic cytokines chemokine (CXC motif) ligand 1 $(\mathrm{KC})$, macrophage inflammatory protein (MIP)-2 and chemokine (CXC motif) ligand 5 (LIX), recruiting PMNs into the lung. Accordingly, attachment of L. pneumophila to cultured mouse peritoneal macrophages increased steady-state levels of cellular mRNAs encoding the cytokines IL- $1 \beta$, IL- 6 and GM-CSF, and the chemokines MIP-1 $\beta$, MIP-2 and KC [28]. Since PMN recruitment was seen in Legionella pneumonia in humans [29] and mice [30], and its blockage increased mortality in the A/J mouse model [27], alveolar epithelium may play an important role in orchestrating the immune response against Legionella.

Recruited monocytes were activated by the Th1 cytokines IFN- $\gamma$ and TNF- $\alpha$; IFN- $\gamma$ promotes Legionella clearance in macrophages [31], and transgenic overexpression of IFN- $\gamma$ in A/J mice reduces the bacterial burden [32]. Since IFN- $\gamma$ was also found to be crucial to immune defence against Listeria monocytogenes in mice [33] and humans [34], an important role of IFN- $\gamma$ in host defence against intracellular bacteria, including Legionella, has to be considered. Similarly, TNF- $\alpha$ promoted L. pneumophila clearance in human monocytes and proved to be protective in mice [35]. As release of both cytokines was reduced by inhibition of p38 MAPK, this pathway might be crucial to an effective immune response in L. pneumophila infection.

L. pneumophila-infected A549 cells did not, however, release Th1 cytokine IL-12 (p70), Th2 cytokines IL-5, -10 or -13 , or the lymphoid and myeloid growth factors IL-7 and GM-CSF.

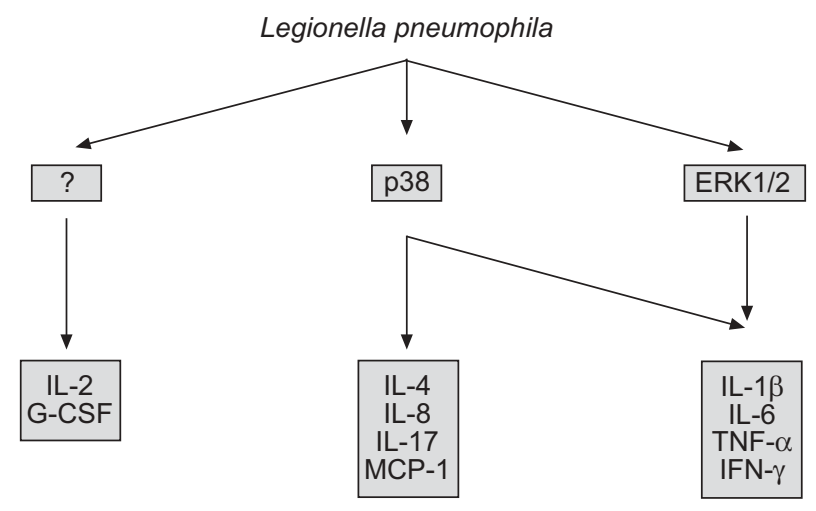

FIGURE 6. Legionella pneumophila induces release of a cytokine pattern differentially dependent on p38 mitogen-activated protein kinase (MAPK) and extracellular signal-regulated kinase (ERK) 1/2 activity. L. pneumophila infection of the human alveolar A549 cell line leads to activation of p38 MAPK and ERK1/2 and to cytokine release. Secretion of interleukin (IL)-2 and granulocyte colonystimulating factor (G-CSF) are not effected by kinase inhibition; IL-4, -8 and -17 and monocyte chemoattractant protein (MCP)-1 are blocked by p38 MAPK inhibition; and IL-1 $\beta$, IL-6, tumour necrosis factor (TNF)- $\alpha$ and interferon (IFN)- $\gamma$ also depend on ERK1/2 activity.

Interestingly, high IL-12 (p70) levels accompanied decreased mortality in A/J mice with L. pneumophila infection [27]. Expression was also found in human L. pneumophila pneumonia [25], and it could be produced by Legionella-exposed dendritic cells [36], but alveolar epithelium does not seem to be a source of this cytokine. In contrast, IL-10 reversed the Legionella-protective effects of IFN- $\gamma$ [37]. Taken together, $L$. pneumophila-infected human alveolar epithelial cells secreted chemotactic CC and CXC chemokines, as well as Th1 and Th2 chemokines (fig. 6). Of these, TNF- $\alpha$, IL-1 $\beta,-6$ and -8 and G-CSF were considered as uniform inflammatory reaction factors, e.g. induced by TLR2, whereas IFN- $\gamma$, IL-2, -4 and -17 and MCP-1 seem to be part of a pathogen-specific reaction [38]. Thus, Legionella-infected alveolar epithelial cells may potently and specifically contribute to the regulation of the host immune response in legionellosis.

In order to gain more insight into alveolar epithelial cell activation by L. pneumophila, expression of the important chemotatic cytokine IL-8 was analysed in more detail. $L$. pneumophila serogroup 1 strains 130b, Philadelphia 1, JR32 and Corby induced IL-8 secretion by infected A549 cells. Philadelphia 1-derived strain JR32 induced IL-8 expression to a lesser extent than the other strains in lung epithelial cells, underlining existing differences between these strains. In accordance with the recent findings of HAwN et al. [7], REN et al. [39] and MOLOFSKY et al. [40], experiments using a Corby fla $\mathrm{A}$ knockout mutant strain indicated that recognition of flagellin by TLR 5 or other possibly intracellular receptors seems to be essential to the early induction of IL-8 release in alveolar epithelial cells in vitro. Moreover, removal or killing (gentamicin) of extracellular bacteria reduced IL-8 release by A549 cells significantly.

In addition, data obtained using a JR32 $\operatorname{dot} A$ knockout mutant indicated that type IVB-secreted effectors do not seem to be 
essential to the early induction of IL-8 release in alveolar epithelial cells in vitro. Furthermore, this implies that bacterial replication is not necessary for induction of IL-8 release. However, CHANG et al. [23] have found that knockout of dotG/ icmE in L. pneumophila strain 80-045 reduced cytokine expression at later time points [23]. L. pneumophila genomes showed marked plasticity and diversity, as recently demonstrated, for example, for the strains Paris and Lens [5], and showed different expression patterns of pathogenetic factors. The physiological importance of such differences is furthermore highlighted by, for example, the observation that Philadelphia 1-derived strain JR32 induced IL-8 expression to a lesser extent in lung epithelial cells. Thus, it cannot be ruled out that the importance of a particular virulence factor may vary between infections with different L. pneumophila strains. Moreover, different genes within the icm/dot loci were manipulated by mutagenesis. In accordance with CHANG et al. [23], the time course of IL-8 mRNA induction by the JR32 strain or $\operatorname{dot} A$ knockout mutant did not differ up to $4 \mathrm{~h}$. Overall, it seems reasonable that recognition of extracellular Legionella by TLRs initially contributes to alveolar epithelial activation $[6,7]$.

Activation of p38 MAPK has been shown to contribute to bacteria-related expression of IL-8 in infected lung epithelial cells [11], and WELSH et al. [41] found that p38 MAPK and Janus kinase were activated early during the uptake of L. pneumophila by macrophages. In lung epithelial cells, p38 MAPK activation $60 \mathrm{~min}$ after infection was critical to the release of all induced cytokines, with the exception of IL-2 and G-CSF, but seems not to be necessary for invasion of the cells (data not shown). Thus, cell-specific effects should be considered concerning replication of L. pneumophila. Interestingly, although ERK2 kinase was activated in infected epithelium, ERK kinase activity contributed to a lesser extent to epithelial cell activation with respect to cytokine and chemokine release. Besides p38 MAPK activity, stimulation of IL-8 expression was dependent upon activation of the transcription factor NF- $\mathrm{KB}$ in L. pneumophila-infected epithelium, as was shown for Streptococcus pneumoniae in lung epithelial cells [11]. Further experiments addressing the role of the different pathogenic factors of Legionella, such as lipopolysaccharide, flagella or hydrolysing enzymes, for the activation of these important pro-inflammatory pathways are needed in order to gain more insight into the molecular mechanisms involved.

In summary, it is shown here that Legionella pneumophila infection induced strong chemokine and cytokine release in human alveolar epithelial A549 cells. Expression of these molecules depends predominantly upon activation of the p38 mitogen-activated protein kinase pathway and nuclear factorкB-dependent gene transcription in A549 cells. Overall, activation of alveolar epithelium seems to contribute significantly to the orchestration of the immune response in legionellosis.

\section{ACKNOWLEDGEMENTS}

The excellent technical assistance of J. Hellwig and S. Schapke (Dept of Internal Medicine/Infectious Diseases and Respiratory Medicine, Charité - Universitätsmedizin Berlin, Berlin, Germany) and K. Rydzewski (Robert Koch Institute, Berlin, Germany) is greatly appreciated.

\section{REFERENCES}

1 Vergis EN, Akbas EA, Yu VL. Legionella as a cause of severe pneumonia. Semin Respir Crit Care Med 2000; 21: 295-304.

2 Swanson MS, Hammer BK. Legionella pneumophila pathogesesis: a fateful journey from amoebae to macrophages. Annu Rev Microbiol 2000; 54: 567-613.

3 Molmeret M, Bitar DM, Han L, Kwaik YA. Cell biology of the intracellular infection by Legionella pneumophila. Microbes Infect 2004; 6: 129-139.

4 Neild AL, Roy CR. Immunity to vacuolar pathogens: what can we learn from Legionella? Cell Microbiol 2004; 6: 1011-1018.

5 Cazalet C, Rusniok C, Bruggemann H, et al. Evidence in the Legionella pneumophila genome for exploitation of host cell functions and high genome plasticity. Nat Genet 2004; 36: 1165-1173.

6 Girard R, Pedron T, Uematsu S, et al. Lipopolysaccharides from Legionella and Rhizobium stimulate mouse bone marrow granulocytes via Toll-like receptor 2. J Cell Sci 2003; 116: 293-302.

7 Hawn TR, Verbon A, Lettinga KD, et al. A common dominant TLR5 stop codon polymorphism abolishes flagellin signaling and is associated with susceptibility to Legionnaires' disease. J Exp Med 2003; 198: 1563-1572.

8 Hawn TR, Verbon A, Janer M, Zhao LP, Beutler B, Aderem A. Toll-like receptor 4 polymorphisms are associated with resistance to Legionnaires' disease. Proc Natl Acad Sci USA 2005; 102: 2487-2489.

9 Strieter RM. Interleukin-8: a very important chemokine of the human airway epithelium. Am J Physiol Lung Cell Mol Physiol 2002; 283: L688-L689.

10 Hippenstiel S, Opitz B, Schmeck B, Suttorp N. Lung epithelium as a sentinel and effector system in pneumonia - molecular mechanisms of pathogen recognition and signal transduction. Respir Res 2006; 7: 97.

11 Schmeck B, Zahlten J, Moog K, et al. Streptococcus pneumoniae-induced p38 MAPK-dependent phosphorylation of RelA at the interleukin-8 promotor. J Biol Chem 2004; 279: 53241-53247.

12 Maruta K, Miyamoto H, Hamada T, Ogawa M, Taniguchi H, Yoshida S. Entry and intracellular growth of Legionella dumoffii in alveolar epithelial cells. Am J Respir Crit Care Med 1998; 157: 1967-1974.

13 Edelstein PH, Nakahama C, Tobin JO, et al. Paleoepidemiologic investigation of Legionnaires disease at Wadsworth Veterans Administration Hospital by using three typing methods for comparison of legionellae from clinical and environmental sources. J Clin Microbiol 1986; 23: 1121-1126.

14 Fraser DW, Tsai TR, Orenstein W, et al. Legionnaires' disease: description of an epidemic of pneumonia. $N$ Engl J Med 1977; 297: 1189-1197.

15 Wiater LA, Sadosky AB, Shuman HA. Mutagenesis of Legionella pneumophila using Tn903 dlllacZ: identification of a growth-phase-regulated pigmentation gene. Mol Microbiol 1994; 11: 641-653.

16 Sadosky AB, Wiater LA, Shuman HA. Identification of Legionella pneumophila genes required for growth within and killing of human macrophages. Infect Immun 1993; 61: 5361-5373. 
17 Edelstein PH. Improved semiselective medium for isolation of Legionella pneumophila from contaminated clinical and environmental specimens. J Clin Microbiol 1981; 14: 298-303.

18 Schmeck B, Huber S, Moog K, et al. Pneumococci induced TLR- and Rac1-dependent NF- $\kappa B$-recruitment to the IL-8 promoter in lung epithelial cells. Am J Physiol Lung Cell Mol Physiol 2006; 290: L730-L737.

19 Schmeck B, Moog K, Zahlten J, et al. Streptococcus pneumoniae induced c-Jun-N-terminal kinase- and AP-1-dependent IL-8 release by lung epithelial BEAS-2B cells. Respir Res 2006; 7: 98.

20 Schmeck B, Beermann W, van Laak V, et al. Intracellular bacteria differentially regulated endothelial cytokine release by MAPK-dependent histone modification. J Immunol 2005; 175: 2843-2850.

21 Opitz B, Puschel A, Schmeck B, et al. Nucleotide-binding oligomerization domain proteins are innate immune receptors for internalized Streptococcus pneumoniae. J Biol Chem 2004; 279: 36426-36432.

22 Bergmann M, Barnes PJ, Newton R. Molecular regulation of granulocyte macrophage colony-stimulating factor in human lung epithelial cells by interleukin (IL)-1 $\beta$, IL-4, and IL-13 involves both transcriptional and post-transcriptional mechanisms. Am J Respir Cell Mol Biol 2000; 22: 582-589.

23 Chang B, Amemura-Maekawa J, Kura F, Kawamura I, Watanabe H. Expression of IL- 6 and TNF- $\alpha$ in human alveolar epithelial cells is induced by invading, but not by adhering, Legionella pneumophila. Microb Pathog 2004; 37: 295-302.

24 Diez E, Lee SH, Gauthier S, et al. Bircle is the gene within the Lgn1 locus associated with resistance to Legionella pneumophila. Nat Genet 2003; 33: 55-60.

25 Tateda K, Matsumoto T, Ishii Y, et al. Serum cytokines in patients with Legionella pneumonia: relative predominance of Th1-type cytokines. Clin Diagn Lab Immunol 1998; 5: 401-403.

26 Fernandez-Serrano S, Dorca J, Coromines M, Carratala J, Gudiol F, Manresa F. Molecular inflammatory responses measured in blood of patients with severe communityacquired pneumonia. Clin Diagn Lab Immunol 2003; 10: 813-820.

27 Tateda K, Moore TA, Newstead MW, et al. Chemokinedependent neutrophil recruitment in a murine model of Legionella pneumonia: potential role of neutrophils as immunoregulatory cells. Infect Immun 2001; 69: 2017-2024.

28 Yamamoto $Y$, Klein TW, Friedman H. Induction of cytokine granulocyte-macrophage colony-stimulating factor and chemokine macrophage inflammatory protein 2 mRNAs in macrophages by Legionella pneumophila or Salmonella typhimurium attachment requires different ligand-receptor systems. Infect Immun 1996; 64: 3062-3068.
29 Winn WC Jr. Myerowitz RL.: The pathology of the Legionella pneumonias. A review of 74 cases and the literature. Hum Pathol 1981; 12: 401-422.

30 Brieland J, Freeman P, Kunkel R, et al. Replicative Legionella pneumophila lung infection in intratracheally inoculated A/J mice. A murine model of human Legionnaires' disease. Am J Pathol 1994; 145: 1537-1546.

31 Skerrett SJ, Martin TR. Recombinant murine interferongamma reversibly activates rat alveolar macrophages to kill Legionella pneumophila. J Infect Dis 1992; 166: 1354-1361.

32 Deng JC, Tateda K, Zeng X, Standiford TJ. Transient transgenic expression of gamma interferon promotes Legionella pneumophila clearance in immunocompetent hosts. Infect Immun 2001; 69: 6382-6390.

33 Portnoy DA, Schreiber RD, Connelly P, Tilney LG. Gamma interferon limits access of Listeria monocytogenes to the macrophage cytoplasm. J Exp Med 1989; 170: 2141-2146.

34 Roesler J, Kofink B, Wendisch J, et al. Listeria monocytogenes and recurrent mycobacterial infections in a child with complete interferon- $\gamma$-receptor (IFN $\gamma$ R1) deficiency: mutational analysis and evaluation of therapeutic options. Exp Hematol 1999; 27: 1368-1374.

35 Skerrett SJ, Bagby GJ, Schmidt RA, Nelson S. Antibodymediated depletion of tumour necrosis factor- $\alpha$ impairs pulmonary host defenses to Legionella pneumophila. J Infect Dis 1997; 176: 1019-1028.

36 Kikuchi T, Kobayashi T, Gomi K, et al. Dendritic cells pulsed with live and dead Legionella pneumophila elicit distinct immune responses. J Immunol 2004; 172: 1727-1734.

37 Park DR, Skerrett SJ. IL-10 enhances the growth of Legionella pneumophila in human mononuclear phagocytes and reverses the protective effect of IFN- $\gamma$ : differential responses of blood monocytes and alveolar macrophages. $J$ Immunol 1996; 157: 2528-2538.

38 Jenner RG, Young RA. Insights into host responses against pathogens from transcriptional profiling. Nat Rev Microbiol 2005; 3: 281-294.

39 Ren T, Zamboni DS, Roy CR, Dietrich WF, Vance RE. Flagellin-deficient Legionella mutants evade caspase-1- and Naip5-mediated macrophage immunity. PLoS Pathog 2006; 2: e18.

40 Molofsky AB, Byrne BG, Whitfield NN, et al. Cytosolic recognition of flagellin by mouse macrophages restricts Legionella pneumophila infection. J Exp Med 2006; 203: 1093-1104.

41 Welsh CT, Summersgill JT, Miller RD. Increases in c-Jun Nterminal kinase/stress-activated protein kinase and p38 activity in monocyte-derived macrophages following the uptake of Legionella pneumophila. Infect Immun 2004; 72: 1512-1518. 